\title{
Considerations Regarding Donation and Value Co-Creation in Times of COVID-19 Pandemic
}

\author{
Renata Klafke $^{1,2}$ (1) Claudia T. Picinin ${ }^{3} \cdot$ Diego G. Chevarria $^{1}$
}

Received: 26 November 2020/Accepted: 10 July 2021 / Published online: 13 August 2021

(C) Global Institute of Flexible Systems Management 2021

\begin{abstract}
This paper examines the phenomenon of strategic donation (including fundraising and intention to donate) through the lens of value co-creation before and after the outbreak of the COVID-19 in non-profit organizations (NPOs). The methodology was based on interviews and statistical analyses of online data. The qualitative results demonstrated that within NPOs, neither the marketing strategy nor the fundraising has been greatly affected by the COVID-19 pandemic. NPOs employ a variety of strategies, including value co-creation activities (events), which is a key element in influencing engagement and donation. The quantitative findings showed that "dialogue" is the most frequent of the value co-creation elements (dialogue, access, risk sharing, and transparency$D A R T$ ) in the media (posts) under consideration. In general, linear regression indicated that, after the beginning of the pandemic, these DART elements may predict online interaction and intention to donate. Shares and comments had a weak $R^{2}$ before the pandemic outbreak and a strong
\end{abstract}

Renata Klafke

nena.klafke@gmail.com

Claudia T. Picinin

claudiapicinin@utfpr.edu.br

Diego G. Chevarria

diego.chevarria@farroupilha.ifrs.edu.br

1 Instituto Federal Do Rio Grande Do Sul (IFRS), Av. São Vicente - Cinquentenário, Farroupilha, Rio Grande do Sul, Brazil

2 UFPR - Universidade Federal do Paraná, Av. Pref. Lothário Meissner, 3400 - Jardim Botânico, Curitiba, PR CEP: 80210-170, Brazil

3 Universidade Tecnológica Federal Do Paraná (UTFPR), R. Doutor Washington Subtil Chueire 330 - Jardim Carvalho, Ponta Grossa, Parana, Brazil
$R^{2}$ after it; that may be explained by the fact that people spent more time online after the outbreak.

Keywords COVID-19 - Donation · Marketing strategies · Non-profit organizations

\section{Introduction}

Because of the COVID-19 outbreak, many organizations had to undergo drastic changes, readapting their communication and marketing strategies. For example, the marketing strategies of pharmaceutical industry to influence physician-prescribing habits by means of visits of medical representants, samples for trials and gifts shifted from inperson meetings to chat messengers and social media networks (Chiplunkar et al., 2020). However, changing marketing strategy can be even more challenging for non-profit organizations (NPOs) because of the social challenges and budgetary constraints these organizations face. As a result, it is of great interest to examine whether strategies may be used to increase or keep donations, especially in times of public calamity.

The COVID-19 pandemic has had a significant influence on numerous sectors, particularly those involving social health systems (Paramita et al., 2021; Tamet al., 2021; Ufua et al., 2021; Vergara et al., 2021). Some nations have a shortage of qualified health professionals, equipment, medications, and, most importantly, space. Those who do not have health insurance or who have been financially damaged by the pandemic are appealing to nonprofit organizations for help.

As capitalism stands as the most predominant approach, it may be inferred that fundraising is an important way to guarantee the organizational survival (Schumpeter, 2010), 
as NPOs depend on fundraisings to accomplish their missions (Avner, 2016). In this regard, it is critical for nonprofits to understand their market and establish successful marketing strategies in order to attract the interest of new donors or volunteers.

Given that such markets are driven more by collaboration than by competition, (Vargo \& Lusch, 2016), we decided to investigate the phenomenon of donation through the perspective of value co-creation between the donor and NPO.

To this moment, the analysis of fundraising in NPOs has been presented, mostly, in terms of branding (Gregory et al., 2019), and market orientation (Chad, 2013; Kaur \& Kumar, 2017; Levine \& Zahradnik, 2012; Modi \& Mishra, 2010). Surprisingly, however, the literature lacks more evidence on value co-creation as a strategic resource for NPOs' fundraising activities. For example, Namisango and Kang (2018) research focus on value co-creation of NPOs' services and their study is anchored to the sociomaterialism perspective and solely on positivism methodology. Ours is a very specific context (pre- and post-COVID-19 outbreak), and we used a multi-method study, which adds not only additional objectivity to the research, but also exploratory qualitative data (Eisenhardt, 1989; Yin, 2015; Gummesson, 2017), as value is always determined in a unique and phenomenological way by the beneficiary (Vargo \& Lusch, 2008).

Regarding the context of this study, the marketing literature has many recent papers dedicated to the understanding of marketing strategies in many different contexts, such as in tourism (Alisher, 2017; Riyadi et al., 2019); in B2B (Vieira et al., 2019; Wright et al., 2019) or international markets (Pomirleanu et al., 2016; Samiee and Chirapanda, 2019). In the context of NPOs, a recent theoretical review (Maier et al., 2016) revealed that the research has focused on understanding the similarities and differences between these and for-profit companies. Other studies emphasize the relationship of power in NPO (Fyall, 2016) and governance (Van Puyvelde et al., 2016). There is little theoretical, and even less empirical evidence on whether and how value co-creation influences donation in NPOs as a strategic means. Hence, it is expected that the present study can enlarge the empirical studies on this phenomenon.

Finally, besides contributing to the marketing literature, this research has a very strong human and social appeal, because it advances theories and situations that influence our society, and this is what social science is about, as echoed by Tihanyi (2020). After all, we are investigating a significant managerial reality and its challenges.

\section{Theoretical Background}

\section{Marketing Strategy: A Brief Recall}

According to Hunt's, 2018 essay, marketing has reached a new era: it intends to influence and reflect the way scholars approach marketing problems, particularly in terms of strategy studies, and how its research truly affects practice. Hunt (2018) emphasizes the fact that current problems differ greatly from previous ones. The author also points out that it is currently much more difficult to publish traditional marketing strategy than consumer research focused papers. The author argues that it may be easier to publish a consumer behaviour research because these scholars are primarily focused on behaviours. Scholars seek out on the field to comprehend them, whereas marketing strategy scholars aim to explain the thought processes and test theories, rather than "contributing" to society. In this way, this research addresses a new situational problem: the COVID-19 pandemic and NPO strategies for dealing with this fact, as well as the publication of a marketing strategy paper, because, according to Hunt (2018), marketing strategy scholars are more concerned with testing theories, than with impacting society.

Nonetheless, strategy and consumers are essential in every business aiming to achieve performance success (Varadarajan, 2010). Most significantly, in a context of constant changes (due to the current pandemic), this means being prepared to act with a systemic vision, efficiency, and speed not just for the organization, but also for the whole system, which includes suppliers, workers, and customers:

Marketing strategy is an organization's integrated pattern of decisions that specify its crucial choices concerning products, markets, marketing activities and marketing resources in the creation, communication and/or delivery of products that since value to customers in exchanges with the organization and thereby enables the organization to achieve specific objectives (Varadarajan, 2010).

As NPOs behave more like businesses, they are exposed to increased scrutiny of their management practices (Ghosh, 2019). NPOs, like any other organization, must employ marketing techniques to attract contributors and enhance donations.

Successful non-profits must constantly demonstrate progress towards their mission, release financial reports, communicate the organization's "story" to draw attention to the work they provide, and communicate transparency both to their funders and the public in order to compete for resources, particularly financial donations (Blouin et al., 
2018; Epstein, 2018). These attitudes may be seen as strategies since they integrate decisions and communicate what they offer/deliver, as stated above by Varadarajan (2010).

To some extent, there appears to be agreement regarding market orientation and its relevance in terms of fundraising in the context of non-profits (Kara et al., 2004; Macedo \& Pinho, 2006). Market orientation entails using better organizational abilities to understand and satisfy customers (Kohli \& Jaworski, 1990). In particular, Mahmoud and Yusif (2012) suggest that NPOs' market-oriented behaviours should extend beyond just meeting overall needs of their consumers (final beneficiaries). Non-profits, on the other hand, should emphasize long-term benefits for the community in which they operate as well as society as a whole (Macedo \& Pinho, 2006; Mahmoud \& Yusif, 2012). Still, some authors argue contrarily, stating that market orientation is not a relevant concept for NPOs because their mission (and what they offer as a product or service) cannot be changed according to shifts in a market's needs (Dolnicar \& Lazarevski, 2009). Other methods of fundraising include market segmentation, advertising, and engaging with the community through various means (Dolnicar \& Lazarevski, 2009).

\section{Value Co-creation in the Marketing Literature and in NPOs}

Studies concerning value co-creation in NPOs should be conducted for the same reasons that actions of co-creation are designed commercially in profit organizations, that is, in order to develop new products or services, or to make consumers loyal, thus increasing their engagement with the organization, just to name a few.

Value co-creation is generally considered an evolution of the value creation concept: organizations create value by means of the products they bring to the market. However, in a value co-creation scenario, companies can only propose value, which will be determined as value by the customer when he/she engages with the product/service offered (Grönroos \& Ravald, 2011). In the third sector, NPOs propose value and the community itself is the final beneficiary, the receiving end of the services provided.

Dialogue, access, risk sharing and transparency (DART), according to Prahalad and Ramaswamy (2004), are aspects of value co-creation. Co-creation occurs through collaborative acts such as co-production, knowledge exchange, collaboration, and the DART components (Payne et al., 2008; Vargo \& Lusch, 2004).

Regarding the process of value co-creation, Payne et al. (2008) argue that it originates from "outside-in" the organization, as value co-creation begins with a proposal. This proposal starts with the understanding of "value" for the clients. The value identification process, as well as its creation, encompasses mechanisms, activities and interactions that support value creation as a whole (Payne et al., 2008).

From a value co-creation perspective-that is, the interaction between groups of donors and NPOs through donation-it is assumed that people are more susceptible to donate when actors co-create value through dialogue, access, transparency and risk sharing (dart).

In marketing strategy, researchers have been mainly interested in the antecedent elements that influence the process of co-creation (Neghina et al., 2015; Zhang \& Chen, 2008). Others have focused on assessing value cocreation in specific segments, such as tourism and health care system (Oliveira \& Panyik, 2015; Payne et al., 2008). In the behavioural literature, however, the studies have delved into the motivation that drives participants during the value co-creation process, particularly in terms of attitudes (Chen et al., 2019; Payne et al., 2008). When it comes to the context (in this case NPOs), value co-creation has attracted greater attention from scholars, as stated by Austin and Seitanidi (2012) and Bryson et al. (2017). Still, most of the researches have been limited to describing the process of value co-creating solely from the consumer's perspective (Austin and Seitanidi, 2012; Kohtamäki and Rajala, 2016; Bryson et al., 2017); thus, we describe the process from both the donor's and NPOS' viewpoint.

\section{Methodology}

The purpose of this study was to find answers to two questions. The first was about NPOs' fundraising marketing strategies, and the second was about value co-creation in donation and donation intention practices. While the former regards the specific context of NPOs' strategies to fundraise before and after the COVID-19 outbreak, the latter approaches the phenomenon more generally, but also providing insights as to value co-creation donation and intention to donate in the context of the novel COVID-19 outbreak.

1) What key strategies did non-profits employ to draw societal attention to their concerns during the pandemic? We investigated the strategies used by nonprofit organizations before and after the COVID-19 epidemic.

2) What is the general role of value co-creation in fundraising?

In order to study value co-creation as a means of fundraising and to investigate the strategies adopted by the NPOs, the present study takes a qualitative and quantitative approach (multiple method). Through the semi-structured 
script, the qualitative part investigates strategic, value cocreation and donation specificities through the eyes of the participants (donors and NPOs), while the quantitative part assesses the data in an objective manner. Because the phenomena of value co-creation is new, complex, and surrounded by personal situations and experiences (Baker \& Saren, 2016; Vargo \& Lusch, 2008), a qualitative study appears to be congruent with the phenomenon's characteristics.

Furthermore, donation practices from a perspective of value co-creation will also be verified - that is, whether the interaction with value co-creation elements (DART) explain donation intentions. A quantitative (statistical) study was undertaken for this purpose. Figure 1 presents the research design of this study:

The first grey square corresponds to the exploratory qualitative research step (Interviews), while the second one refers to the quantitative investigation (Online Data Collection). Both phases are further detailed in accordance with their unique characteristics. It is crucial to highlight that the NPOs and donors were asked for participation approval and official consent (written, through email) to conduct this study during the qualitative stage.

\section{Qualitative Research Strategy: Data Collection and Analysis}

Whenever the phenomenon is new, developing, or contextdependent, a case study strategy is recommended (Eisenhardt, 1989; Gummesson, 2017). Case study interviews allow the understanding of certain reasons, subjacent motivations and may determine or help some hidden dimensions of consumer preferences over specific brands, suppliers, products, services, among others (Gummesson, 2017). This is something that a quantitative approach may overlook. The sample of this study was composed of 2 nationwide known NPOs selected by convenience (2 managers interviewed from each NPO) and 2 donors of each NPO, resulting in 8 interviews. The interviews relied on the use of semi-structured questions to deepen and refine the knowledge about co-creation of value and marketing strategies aimed at increasing fundraising. From these interviews, it was possible to obtain an insight into the actors' perspectives, as well as their awareness of value co-creation actions and elements. Managers' perspectives, in particular, are crucial because they allow us to understand how fundraising strategies are developed in this new economic, social, and political context. These interviews focused on non-profit fundraising strategies, their similarities and differences, and how the NPO and the donor cocreate value. The interviews with donors compared their profiles, such as gender, age, and education. Their background enabled us to learn about the underlying motivations for value co-creation and donations and how they are carried out. All interviews were recorded and transcribed. Each interview was catalogued according to the template in Table 1 for better evaluation of the responses.

To analyse the interviews, a hybrid approach (deductive-inductive) of content analysis was taken using MAXQDA software. The deductive method was employed because it focuses on the theoretical category, while the inductive method highlights new elements expressed by the participants.

In this respect, this study contributed to the understanding of value co-creation from a multi-method perspective since much of the research in the services and marketing literature uses exclusively quantitative approaches. (Valtakoski, 2019).

The systematization of the qualitative approach followed two qualitative research guidelines: Gibbs (2014), Kuckartz and Rädiker (2019). Their systematization approach occurs through: (a) data input into the software or
Fig. 1 Mixed methods research approach, source: Authors (2021)

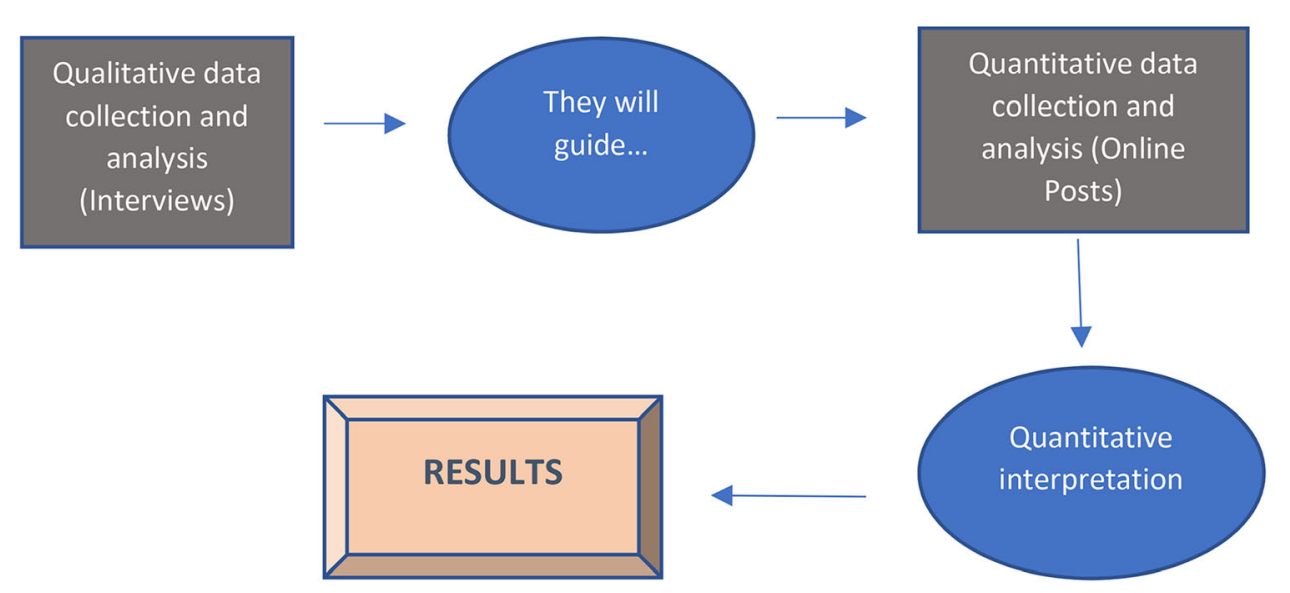

Source: Authors (2021) 
Table 1 Interviewees' record template

\begin{tabular}{lll}
\hline Respondent & Date & Duration \\
\hline 1$)$ & & \\
2) & & \\
\hline
\end{tabular}

Source: Authors (2021)

any other tool that allows systematization, visualization and study of data and ideas; (b) exploration of the material through the broader (floating) coding of data; (c) definition and aggregation of the thematic unit of analysis, which in this project took place through the participant's sentence and/or contextual analysis; (d) confirmation of the categories of analysis using qualitative tools (such as word clouds, word frequencies, lexical analysis, summary grids, cluster and matrix analysis, etc.); and, finally, (e) review of data and results.

\section{Quantitative Research Strategy: Data Collection}

The quantitative research collected data from online posts. We sought to check whether NPO postings (inductively categorized into DART elements) affected people's reactions and interactions on a digital platform (Twitter). This assessment supports evidence for the following proposition: when actors co-create value, people are more likely to donate. According to Da Silva et al. (2020), donation intention may be evaluated in terms of interaction, affection, and positive attitudes. In this sense, likes, shares, and comments are subjected to certain variables.

\section{How to Measure Donation Intention}

Kashif et al. (2015) and Mainardes et al. (2017) are two studies that stand out in terms of analysing individual behaviours in terms of intent to donate to NPOs.

Kashif et al. (2015) sought to identify the factors that contribute to donation in Malaysia. The authors found that past experience and intentions to donate contribute positively to the real behaviour of donating money. That is, past positive donation experience is likely to lead that person to donate again. This is also true regarding the intention of donation.

The majority of research on "intention" believe it to be a mixture of two major independent measures: "attitude" and "subjective norm" (Ajzen, 1991). Subjective norms pertain to institutions, whereas attitudes refer to an individual's positive or negative evaluation of behaviour, a psychological reaction created by consumer evaluation that, if positive, may substantiate behaviour intention (Vargo \& Lusch, 2016).
We hypothesized that donation intentions were derived from "likes" in social media posts including DART elements. This assumption is based on preliminary readings of Lwin and Phau (2014) and Sura et al. (2017), which suggest that attitudes towards non-profits have a substantial effect on donation intention.

It is worth noting a finding on donation intention that arose from the qualitative research (first phase of this study). The majority of non-profit social media followers are current donors or have some involvement with the organization, such as volunteering. Furthermore, people may also follow (online) the organization as a result of their search for the "appropriate" NPO to donate to. In this case, the user will likely engage with the organization, be it by sharing posts online, volunteering for work or making financial donations.

The aforementioned activities are seen as engagement with the NPO (McColl-Kennedy et al., 2015), and three possible social media actions (likes, shares, and comments) indicate that the user is psychologically concerned with the post, and therefore engaged (Kim \& Yang, 2017). Commenting, sharing, and retweeting, on the other hand, require more cognitive effort from the user than simply like (Li, 2017).

This insight suggests that online interactions like "shares" and especially "comments" might be seen as an indication of donation intent or a signal of interest and approval from current donors that they appreciate what is being posted. As a consequence, they are likely to persist donating.

In accordance with the above, this study considered "likes" as including aspects of DART and value co-creation. For the linear regressions, the independent variable was "DART", while the dependent variables were "shares" and "comments".

\section{Sample and Database Selection}

As mentioned earlier in this section, the social network chosen for this study was Twitter. The reason for this choice was its popularity in social media research due to its messaging structure, which includes mentions, message replications (retweets) and likes. Discussions on social media, mainly on Twitter, Facebook and others, have a wide range of topics and in-depth knowledge, which leads to innovation and the co-creation of value (Rathore et al. 2018).

After inductively categorizing the posts according to the DART elements, we quantified the number of likes, shares, and comments in the analysed NPO, aiming to recognise a relationship between the number of publications, shares and comments and DART. The total database consists of 605 posts collected from the Twitter profile of the NPOs 
explored in the qualitative phase. Each "tweet" was analysed according to the following information: likes, retweets/shares, and comments. The data were gathered during the period of July 2019 to June 2020.

NPO-Cancer-408 tweets.

NPO-Exceptional Needs-197 tweets.

The Statistical Package for the Social Sciences (IBM SPSS) software was used, in particular the linear regression (OSL) for a causal analysis in which the independent variables were NPOs' posts being "likes" defined as the antecedent of the value co-creation. The dependent variables were shares/tweets and comments.

\section{Database Preparation}

The data were organized in a broad spreadsheet containing the details of its characteristics, according to Table 2. Then, the posts were inductively classified into the DART elements. Risk sharing (in light grey) was not considered for analysis because this attribute was not identified in the qualitative phase of this study.

\section{Data Analysis}

This study employed statistical techniques to find trends, repeated terms, percentages and relationships, to evaluate the existence of value co-creation practices in online interactions and to compare the results with other findings in the literature. This stage was performed with the usage of SPSS software.

Likes, shares, and comments were separated before and after the COVID-19 pandemic outbreak. Comments and shares were considered donation intention for their deeper degree of psychological involvement with the post, hence engagement (Kim \& Yang, 2017). The DART components have been coded as follows for analytical purposes: 1 (D), 2 (A), 3 (T). All postings were divided into two categories: "before" and "after" the COVID-19 outbreak.

The data were evaluated using descriptive statistics (median and standard deviation) and graphics. "Descriptive statistics are used to organize and describe the characteristics of a set of data", according to Salkind (2016, p. 8). T-tests were performed to test whether there was a statistical difference between the posts examined before and after the pandemic breakout. Additionally, differences in the different types of engagement (like, comment, and share) were also evaluated. The results of the tests reveal that 'shares' present a statistically significant difference when $\mathrm{p}<0.001$. Thus, it was decided to conduct quantitative analyses of each NPO separately. Table 3 shows the results of this T-test.

Finally, to see whether the DART elements had any effect on donation intention, a linear regression was run for each NPO. Linear regression is a statistical technique used to predict or explore variables relations, and its scalar response to a dependent variable (Angrist \& Pischke, 2008). The coefficient, often known as $R^{2}$, is the primary

Table 2 Database organization

\begin{tabular}{|c|c|c|}
\hline Variable & Explanation & Posts inductively classified according to DART elements \\
\hline Likes & Total of likes that the respective post received & N/A \\
\hline Comments & Total of user comments the respective post received & N/A \\
\hline Retweets & Number of times that users forwarded the post, by retweeting it & N/A \\
\hline Dialogue & $\begin{array}{l}\text { Dialogue means exchange of information and fosters } \\
\text { constructive interaction (of knowledge and experiences) and } \\
\text { the development of a shared beliefs (Gummesson and Mele, } \\
\text { 2003) }\end{array}$ & $\begin{array}{l}\text { Our Dialogue classification includes, but not only: general } \\
\text { information, any TBT post, partnerships realized on the } \\
\text { internet between NPO and other companies, tribute messages, } \\
\text { a reading suggestion, etc. }\end{array}$ \\
\hline Access & $\begin{array}{l}\text { Customers want access to experiences. There is not just the } \\
\text { "owning asset". Ex: drinking an export type coffee in a } \\
\text { supermarket }\end{array}$ & $\begin{array}{l}\text { Our Access includes, but are not limited to: A call to interact } \\
\text { with the NPO, a call to donate to the NPO through its } \\
\text { partners, sales of a product, support to a cause/event directly } \\
\text { related to the NPO, etc. }\end{array}$ \\
\hline Transparency & $\begin{array}{l}\text { Information is more readily available and accessible. Customers } \\
\text { are increasingly able to access knowledge that previously was } \\
\text { not available }\end{array}$ & $\begin{array}{l}\text { It converges the organizational reliability and information given } \\
\text { to the consumer. Without these elements, there is no } \\
\text { possibility and factuality of co-creating value between } \\
\text { organization and consumer (Prahalad \& Ramaswamy, 2004). } \\
\text { These elements (DART) arise from engagement (McColl- } \\
\text { Kennedy et al., 2012). Examples of transparency mainly } \\
\text { include annual reports and donation reports or videos of other } \\
\text { organizations or partnerships donating to the NPO, etc. }\end{array}$ \\
\hline
\end{tabular}

Source: Authors (2021) 
statistical measure of the strength of the relationship between response and predictive factors. It expresses how close the data are to the adjusted regression (Stock and Watson, 2015).

\section{Results and Discussion}

\section{Qualitative Phase}

\section{NPOs' and Donors' Profiles}

Both of the NPOs studied are in Brazil's southern region. NPO-Cancer is a non-profit organization whose mission is to help children and adolescents with cancer, as well as their families. In 2019, the NPO-Cancer aided over 4,000 children across the country.

Two managers from this NPO were interviewed: the first is in charge of the telemarketing (Donation Center Department), and the second is in charge of the marketing sector. Both have a degree in business management and have worked in the third sector for over 8 years.

NPO-Exceptional Needs is a social assistance charity that provides specialized assistance to children with disabilities and their families, free of charge. Two managers were interviewed; the first has acted as the president of the NPO for more than 20 years, while the second manages the social assistance responsibilities of the organization. Both have a degree in their respective areas.

The donors were named by the non-profits. Two regular donors who have made money donations for several years were suggested by the organizations. Table 4 compresses each donor profile:

\section{Qualitative Study Results}

The study showed that for both NPOs, neither fundraising nor marketing strategy activities have been greatly affected by the pandemic. This is because they have taken a more "human" and less technical approach to fundraise. A more humane strategy sensitises the listener: Care and healing stories have been shown to be helpful in capturing the donor's attention and avoiding the individual from hanging up the phone. In this regard, non-profits have essentially two strategies: one that is modern (digital) and one that has a strong social/emotional appeal.

According to NPO-Cancer, when approaching a possible donor, the donation team stresses the human element of the conversation, saying that the donation is saving a life. Simultaneously, there is a call for individuals to take direct responsibility for the cause. As soon as the pandemic broke out and the lockdown was declared, the marketing departments of both NPOs were forced to contact certain donors since the post office was unable to send some payment slips. Managers noted during these phone calls that the pandemic had sensitized individuals that the number of people interested in donating or assisting in other ways (co-creating value) had increased; they did not have to post reports, ask for help, or conceive of any miracle plan. It was merely a charitable effort intended to assist those in most need.

The old method, according to NPO-administrators, was to introduce the institution to the potential donor, demonstrate financial statistics, and explain the organizational structure professionally. The current approach discusses the social benefits that may be achieved for the community, as well as how individuals can generate value with the NPO to help them achieve their social mission. The NPO perceives the donor as a value aggregator. The accomplishment of the social mission is the consequence of the value co-creation. As a result, value co-creation acts as a mechanism of achieving the NPO's social goal.

This appeal to engage - to save a life-is derived from value co-creation. The mission of the NPO is what encourages people to donate. The NPO's mission is what encourages people to donate. It was mentioned that the mission has an impact on people's emotions and is an essential element in the donation process.

In the qualitative phase, engagement may be defined as donation fulfilment, whereas engagement was a sub-category of the organizational strategy variable.

Table 3 T-test of differences between NPOs engagement

\begin{tabular}{|c|c|c|c|c|c|c|c|}
\hline & & \multirow[t]{2}{*}{$\mathrm{t}$} & \multirow[t]{2}{*}{ Sig. (2 tailored) } & \multirow[t]{2}{*}{ Mean difference } & \multirow[t]{2}{*}{ Standard error } & \multicolumn{2}{|c|}{$95 \%$ Standard confidence } \\
\hline & & & & & & Inferior & Superior \\
\hline Like & Equal var. assumed & .887 & .376 & 23.20 & 26.17 & 28.203 & 74.619 \\
\hline Share & Equal var. not assumed & 3.496 & .001 & 13.63 & 3.90 & 5.97456 & 21.298 \\
\hline Comment & Equal var. assumed & 2.260 & .024 & 4.71 & 2.08 & .61824 & 8.818 \\
\hline
\end{tabular}

Source: Authors (2021) 
Table 4 Donors' profile

\begin{tabular}{|c|c|c|c|}
\hline NPO-Cancer donor A (Male) & NPO-Cancer donor R (Female) & $\begin{array}{l}\text { NPO-Exceptional Needs donor V } \\
\text { (Female) }\end{array}$ & $\begin{array}{l}\text { NPO-Exceptional Needs } \\
\text { donor F (Female) }\end{array}$ \\
\hline 64 years old & 62 years old & 67 years old & 65 years old \\
\hline $\begin{array}{l}\text { Graduated in Business } \\
\text { management }\end{array}$ & $\begin{array}{l}\text { Incomplete graduation in Business } \\
\text { management }\end{array}$ & \multirow{2}{*}{$\begin{array}{l}\text { Graduated in Chemistry } \\
\text { Retired, but still teaches at school and } \\
\text { works as a volunteer }\end{array}$} & $\begin{array}{l}\text { Postgraduated in Marketing } \\
\text { and winemaker }\end{array}$ \\
\hline $\begin{array}{l}\text { Retired, but owns an } \\
\text { accounting company }\end{array}$ & $\begin{array}{l}\text { Retired, but donates money and } \\
\text { works as a volunteer }\end{array}$ & & $\begin{array}{l}\text { Owns and administrates some } \\
\text { companies }\end{array}$ \\
\hline
\end{tabular}

Source: Authors (2021)

Marketing strategies such as annual reports and festive events are classified as "social strategies", while other activities permeate the commercial strategy. This is due to the need for these organizations to improve their businesslike image. Nonetheless, there is a strong social appeal connected to the individual being cared by the NPO. And this appeal has an impact on their strategy. Through emotional appeals, NPO-Exceptional Needs engage actors, like suppliers, donors, and politicians. For example, there was an event in which a partner (a well-known fine chocolate company) donated unsold Easter eggs to the NPO as their expiration date neared. This manager emphasizes the cooperation in this exchange relationship because without it, children would never have the opportunity to taste chocolate of this quality. With everything that is received by NPO-Exceptional Needs be it cash or goods, the managers make sure to mention what the resource is reverted to. The money turned into double-sided toilet paper; the fine chocolate provided a special taste and moment for children and parents; the protein (meat) is eaten at the school since it may be the only place where they eat beef, a food item with high added value, among other cases. Such an appeal shapes the NPO's pitch approach, which is aligned with the challenges of working circumstances and may be regarded as a business strategy within logical terms. However, before this becomes a business strategy, there may be an appeal for it, which stems from the hampered conditions NPOs face or their needs.

Appeal involves feelings that emerge in both the strategy and the category of value co-creation. Feelings arise as a consequence of the value created between the donor and the NPO. People's feelings, on the other hand, play an important role in initiating the process of value co-creation. Empathy is a driver for engagement, which may explain why the NPOs analysed publish several images and videos on their websites.

Another consideration is communication between the NPO and society. It does not regard simply managing the NPO with transparency, social responsibility, and indicators as NPOs with certified credibility do not need to demonstrate transparency in society, implying that organizational structure is not really important. The importance, rather, lies in the development of the NPO's identity.

The construction of such identity has received relatively little attention so far. The organizational identity, particularly when directed by its mission and values, must be consistent with the NPO's practice and workforce. It is essential to highlight real patterns of interaction that denote what is central, distinctive, and significant for NPO individuals.

The presentation of the NPO was a component that might result in the person's (un)willingness to engage with the NPO's cause. That is, clarifying the type of work done as well as who is assisted. Such aspects impact value cocreation and may result in donation or refusal to donate. For example, a donor's daughter has stated that she does not donate to non-profit organizations that rehabilitate drug users. Drug addiction, in her perspective, is a choice, not a life condition. A special-needs child has a different appeal than a drug addict. Thus, it can be deduced that the NPO's characteristics and cause can guide the appeal and fundraising strategy.

According to the respondents' comments, networking is mostly seen as a value co-creation strategy. A visit to a NPO is an important experience since it allows people to visualize what is being done, become involved with the projects and the cause, or strengthen the bonds between NPOs and donors.

Another widely used strategy is one that focuses on the digital dimension. Some people donate because of the "internet appeal". Others contribute to show off. NPOs may investigate this desire for social affirmation in order to persuade both current and potential donors to engage. Others' social affirmation may be quite powerful. If a group of people accomplishes something (for example, donates) and posts it on social media, their friends may be impacted as well. According to NPO-Exceptional Needs, online users compete for popularity to become role models. Thus, engagement indicates that the individual is a good 
citizen. Users may know very little about the organization; nonetheless, what counts to them is that they donate and to show it online.

Some people, according to Donor A, co-create in order to achieve something greater for self-promotion, affirmation, or vanity. People frequently try to show to their followers that they "do something good", as if social approval were expected. This attitude contradicts the characteristics of the donors interviewed: Donor $\mathrm{V}$ admits that she donates because of civility. Donor A is likewise extremely discrete person; only family members and other donors are aware that he donates.

A couple of North American YouTubers who adopted a Chinese child are an example of a desire for social affirmation and social approval and self-promotion. Years later, though, the child was returned to his biological family. According to the circumstances of the case, the couple was searching for adoption rather than motherhood, because a "good mother" would not abandon her autistic child. Although the couple got some money, sponsorship, and subscriptions to their social action (adoption), the majority of this support was lost once the cause for the repatriation was revealed.

\section{Quantitative Phase}

\section{NPO-Exceptional Needs}

\section{Descriptive Statistics}

A total of 197 cases were examined. Element (D) was found in 129 posts, element (A) in 65, and element (T) in 3 posts. This demonstrates that this NPO primarily encourages donors and potential donors to engage in conversation.

Figure 2 shows the DART elements separately (before and after the pandemic outbreak).

There was a reduction in all DART elements after the COVID-19 pandemic. Prior to the outbreak, 76 posts categorized as D were observed, and after it 5 posts. We infer that the same happened to other companies too, because of the newness and novelty of the situation, resulting in uncertainty and doubt about what should be posted or communicated as not enough or certain information was available at the time.

Figure 3 compares the moment before and after the pandemic in terms of Total Shares.

Prior to the pandemic, the number of shares averaged 11.31 (from 0-69), with a median of 5 and a standard deviation of 14,273 .

Following the outbreak, the number of shares averaged 16.85 (ranging from $0-265$ ), with a median of 7 and a standard deviation of 38.520. Figure 4 compares the "Total Likes", before and after the pandemic outbreak.

Prior to the pandemic, the average number of likes was 159.83 (with a minimum of 5 and a maximum of 1811), with a median of 54 and a standard deviation of 246,897 . Following the outbreak, the number of likes averaged 104.23 (ranging from 0-1218), with a median of 37 and a standard deviation of 221,912 .

Figure 5 shows a comparison of the "Total Comments" before and after the pandemic outbreak. Before the outbreak, the number of comments averaged 4.41 (minimum of 0 and maximum of 60) had a median of 1 and a standard deviation of 8,627 .

After the outbreak, the number of comments averaged 5.67 (minimum 0 and maximum 61) had a median of 1 and a standard deviation of 10.241 .

The descriptive statistics indicate a decrease in sharing after the outbreak. There was also a considerable decrease in total likes after the pandemic. Total Comments was the only variable observed that raised the average after the pandemic. Users wrote more comments about the organizations' publications. This might be explained by the fact that, after the outbreak, posts were more likely to entertain users, suggesting interactive games that could be done at home with children or promoting useful health information.

Despite these findings, a T-test of the difference in the means of likes, shares, and comments before and after the pandemic revealed that these differences were not statistically significant. Thus, these observed differences might be attributed to fewer postings being written following the pandemic. The results of this test are shown in Table 5 .

\section{Linear regression before and after COVID-19-NPO- Exceptional Needs}

The DART elements were chosen as the independent variable, while shares and comments were chosen as the dependent variables. The inclusion of these variables was motivated by the need to quantify donation intent, as shares and comments, as previously mentioned, are seen to reflect a stronger online involvement (Kim \& Yang, 2017; Li, 2017), therefore, intention to donate. Two linear regression models were developed: one for the time period preceding the COVID-19 pandemic and one for the time period after the outbreak. Deviations from normality had no significant influence on the data shown below, and equality of variances was not assumed.

Table 6 presents the total of each of the unified DART elements before and after the COVID-19 pandemic, and the summary of the linear regression models before and after the outbreak. The dependent variables were Total 
Fig. 2 DART elements separately (before and after the pandemic), source: SPSS (2021)

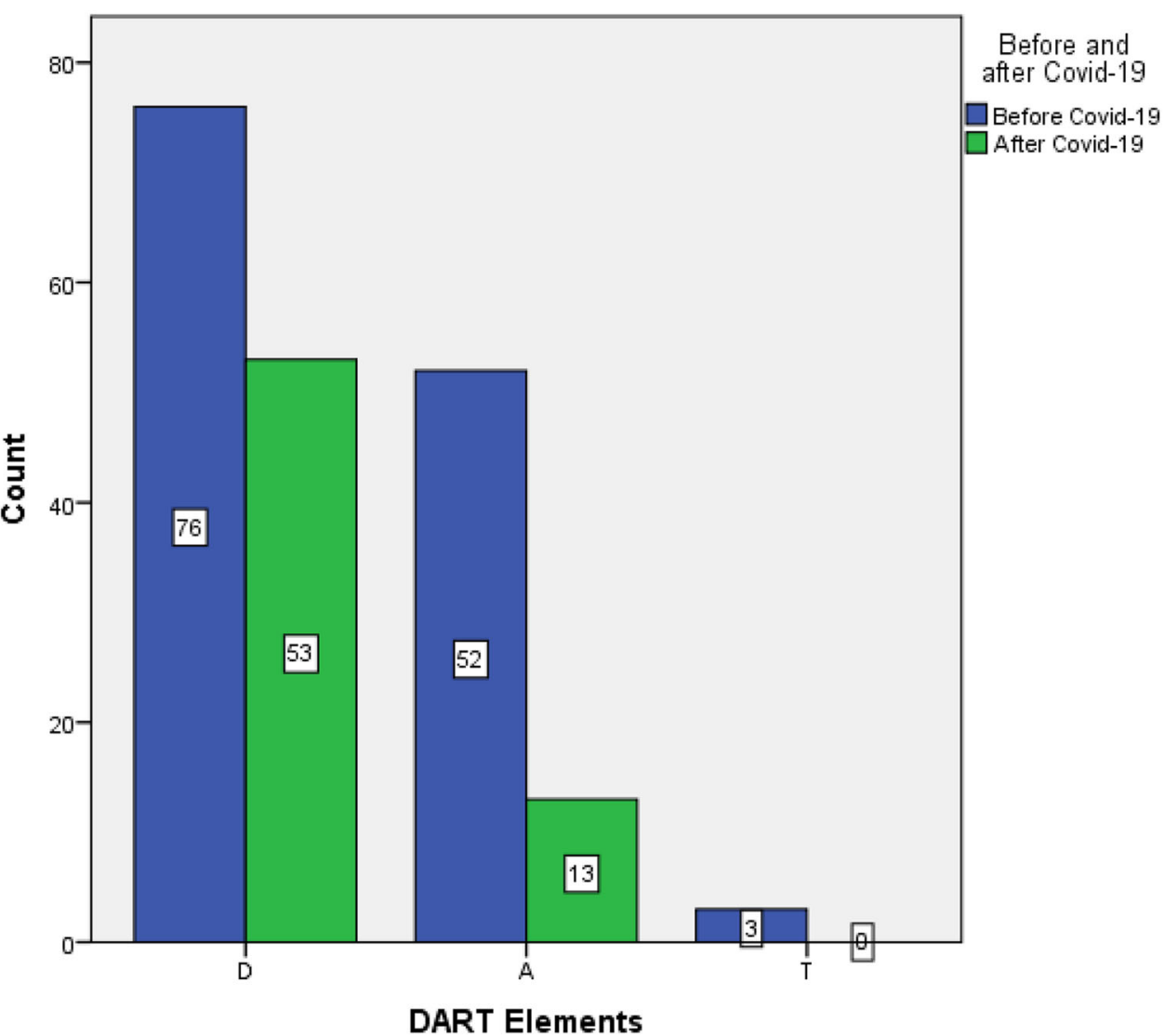

Source: SPSS (2021)
Comments and Total Shares, as resulting of DART elements. The models for the posts before and after pandemic were:

Model 1: Total Shares (Number of Posts) (Dependent Variable) x Total-DART (Number of Posts) (Independent Variable).

Model 2: Total Comments (Number of Posts) (Dependent Variable) x Total-DART (Number of Posts) (Independent Variable).

\section{Before the Pandemic-NPO-Exceptional Needs Model 1} has some predictive power, but it was not high (adjusted $\left.\mathrm{R}^{2}=0.398\right)$. The $\mathrm{P}$-value was $<0.001$. This indicated that previous to the pandemic, the DART components were only moderately (almost $40 \%$ ) able to predict Total Shares, and hence the willingness to donate.

Model 2's predictive power was low (adjusted $\left.\mathrm{R}^{2}=0.294\right)$. The $P$-value was $<0.001$. This indicated that the DART components were unable to predict the Total Comments and, as a result, donor intention to donate prior to the pandemic.

After the Pandemic Outbreak-NPO-Exceptional Needs The predictive power of model 1 was moderate (adjusted
$\left.\mathrm{R}^{2}=0.541\right)$. The $P$-value was $<0.001$. This indicated that the DART elements were only modestly able of predicting Total Shares after the outbreak.

The predictive power of model 2 was likewise moderate (adjusted $\mathrm{R}^{2}=0.571$ ). The $p$-value was $<0.001$, showing that the DART elements were only moderately able to predict Total Comments, and therefore the intention to donate, after the pandemic.

Table 7 summarizes the models for the NPO-Exceptional Needs:

DART elements were unable to predict Total Shares and Total Comments in this NPO before the outbreak. After the outbreak, however, a favourable (moderate) relationship could be found. The NPO-Exceptional Needs' internet strategies did not change much after the pandemic as compared to its strategy before to the outbreak.

One possible reason is that when people were confined and forced to spend more time at home, their internet time increased. Furthermore, when unemployment rose, especially in developing nations, individuals turned to social networking sites such as Facebook, Instagram, and Twitter to release new (personal and informal) businesses. These findings also suggest that the pandemic raised awareness of the need for non-profit organizations. 
Fig. 3 Total Shares (before and after the pandemic), source: SPSS (2021)

Fig. 4 Total Likes (before and after the pandemic), source: SPSS (2021)

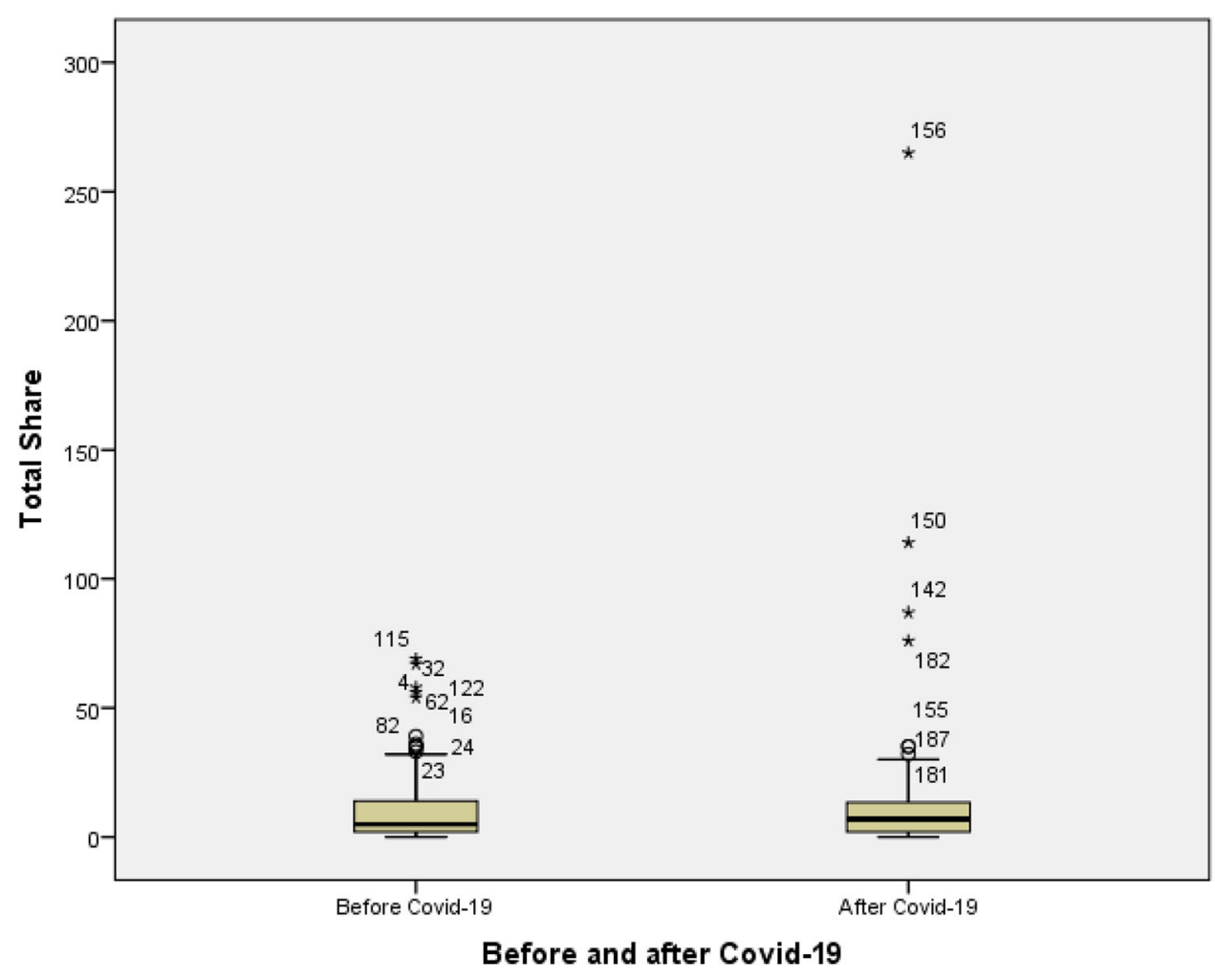

Source: SPSS (2021)

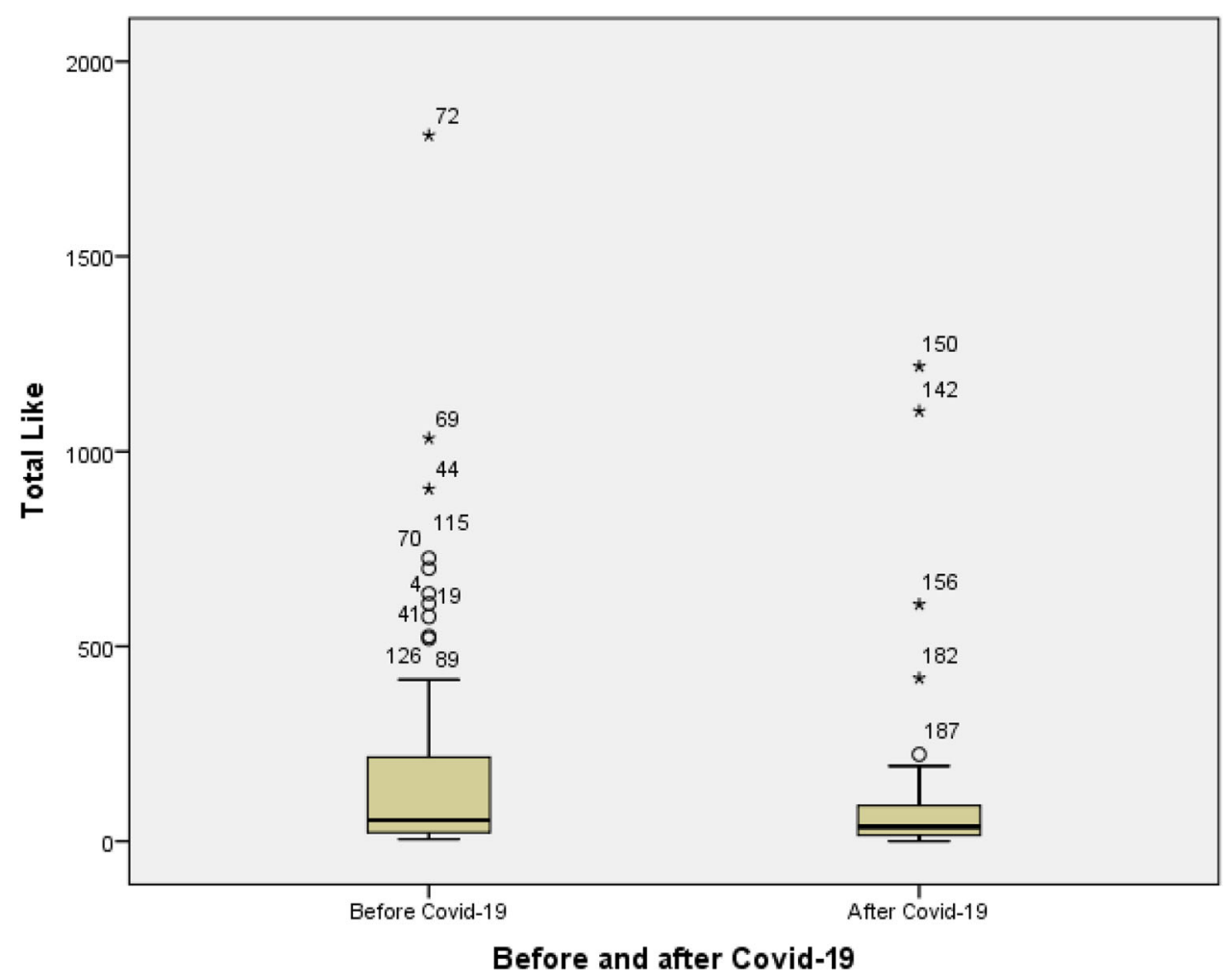

Source: SPSS (2021) 
Fig. 5 Total Comments (before and after the pandemic), source: SPSS (2021)

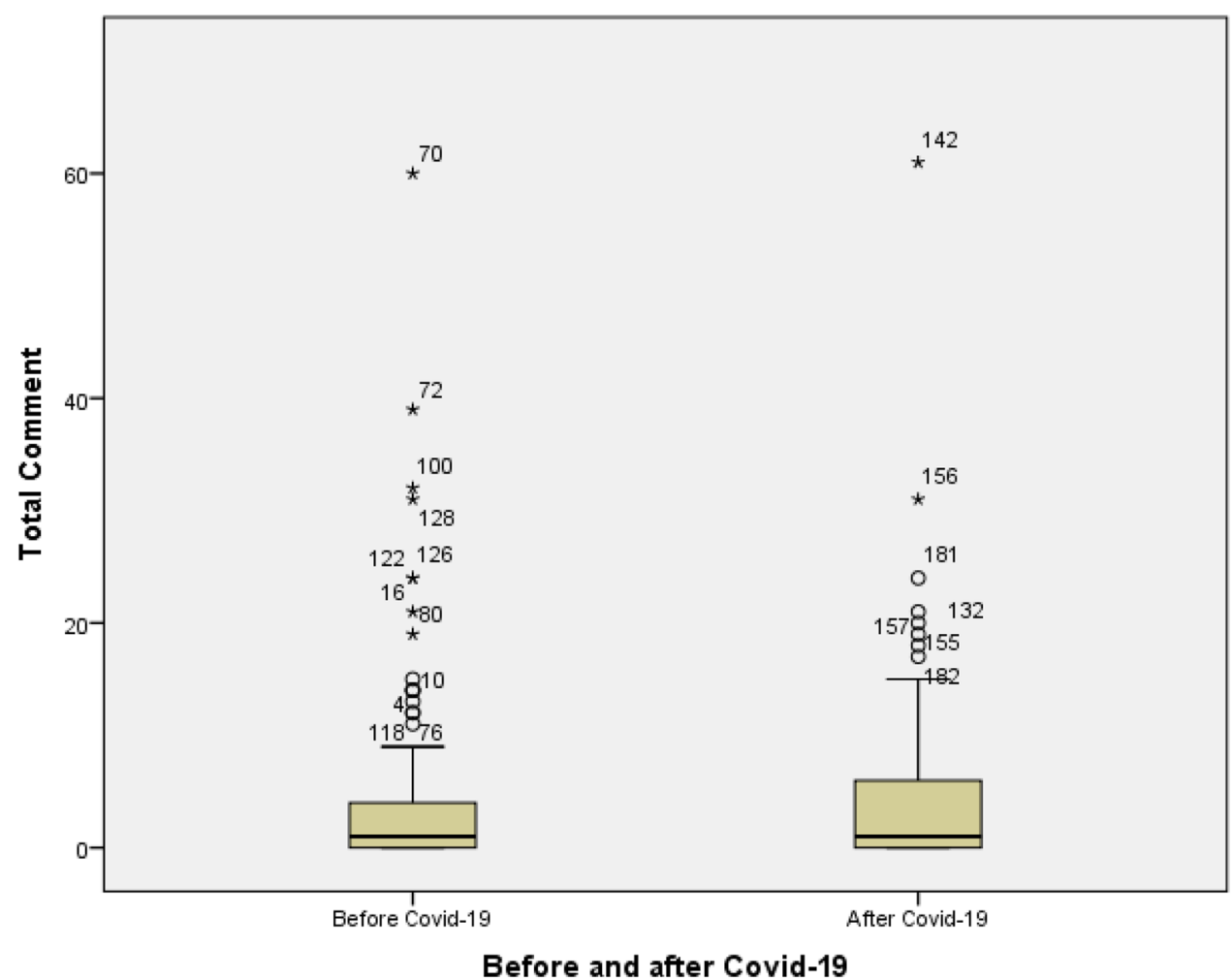

Source: SPSS (2021)

Table 5 T-test of engagement before and after the pandemic

\begin{tabular}{llllllll}
\hline & & $\mathrm{t}$ & Sig. (2 tailored) & Mean difference & Standard error & \multicolumn{2}{c}{ 95\% Standard confidence } \\
\cline { 5 - 8 } & & & & & Inferior & Superior \\
\hline Like & Equal var. assumed & 1.335 & .183 & 49.07 & 36.76 & 23.432 \\
Share & Equal var. assumed & 1.560 & .120 & 5.89 & 3.77 & 13.337 & 1.557 \\
Comment & Equal var. assumed & 1.132 & .259 & 1.98 & 1.75 & 5.440 \\
\hline
\end{tabular}

Source: Authors (2021)

\section{NPO-Cancer}

\section{Descriptive Statistics.}

In total, 405 cases were evaluated, with only one being lost (not counted in the analysis). Element (D) had 204 posts, element (A) had 175 and element (T) had 25.

Figure 6 shows the DART elements separately (before and after the outbreak).

After the COVID-19 pandemic, there was a reduction in all DART elements. Before the pandemic, 160 of the observed were categorized as posts categorized as (D), while after the outbreak only 44 posts were categorized as such.
Figure 7 compares the "Total Share" before and after the COVID-19 pandemic period.

Prior to the pandemic, the average number of shares was 31.72 (with a minimum of 0 and a maximum of 956), with a median of 12 and a standard deviation of 79.847 .

After the pandemic, the number of shares averaged 18.26 (minimum of 1 and maximum of 251), with a median of 10 and a standard deviation of 31,584.

Figure 8 compares the "Total Likes" before and after the outbreak.

Prior to the pandemic, the average number of likes was 188.58 (ranging from 0-3499), with a median of 91.5 and a standard deviation of 359,004 . 
Table 6 Intensity of interaction as a response to DART elements

\begin{tabular}{lll}
\hline Before the COVID-19 & Model 1 (DART to Shares) & Model 2 (DART to Comments) \\
\hline Frequency & $197(100 \%)$ & $197(100 \%)$ \\
$\mathrm{R}$ & 0.635 & 0.547 \\
$\mathrm{R}^{2}$ & 0.403 & 0.299 \\
Adjusted $\mathrm{R}^{2}$ & 0.398 & 0.294 \\
ANOVA (F) & $86.296^{* * *}$ & $54.703 * * *$ \\
Constant (B) & $5.410^{* * *}$ & 1.094 \\
Shares, comments (B) & $0.036^{* * *}$ & $0.22^{* * *}$ \\
\hline After the COVID-19 Outbreak & Model 1 (DART to Shares) & Model 2( DART to Comments) \\
\hline Frequency & $197(100 \%)$ & 197 (100\%) \\
R & 0.740 & 0.760 \\
$\mathrm{R}^{2}$ & 0.548 & 0.578 \\
Adjusted $\mathrm{R}^{2}$ & 0.541 & 0.571 \\
ANOVA (F) & $77.552^{* *}$ & $87.524 * * *$ \\
Constant (B) & 3.295 & 1.189 \\
Shares, comments (B) & $.124 * * *$ & $.048^{* * * *}$ \\
\hline
\end{tabular}

**** $\rho<0.001$

${ }^{* *} \rho<0.05$

$* \rho<0.1$

Source: Authors (2021)

Table 7 NPO-Exceptional results

\begin{tabular}{llll}
\hline Period & Model & Variables & Result \\
\hline Before the pandemic & Model 1 & DART vs Total Shares & Total Shares were slightly influenced by DART \\
& Model 2 & DART vs Total Comments & Total Comments were not influenced by DART \\
After the pandemic outbreak & Model 1 & DART vs Total Shares & Total shares were influenced by dart \\
& Model 2 & DART vs Total Comments & Total Comments were influenced by dart
\end{tabular}

Source: Authors (2021)

After the pandemic, the average number of likes was 148.09 (minimum 9 and maximum 1964), with a median of 80.50 and a standard deviation of 247,165 .

Figure 9 provides a comparison for the number of "Total Comments" before and after the COVID-19 pandemic. Prior to the pandemic, the number of comments averaged 10.70 (from 0-371), with a median of 3 and a standard deviation of 28,796 .

After the pandemic, the number of comments averaged 12.70 (minimum 0 and maximum 264), with a median 5 and a standard deviation of 32.229 .

A significant decrease in the number of posts shared may be noted. Furthermore, when comparing the number of likes before and after the pandemic, it is possible to detect a decrease in the overall number of likes. Overall, "likes" decreased both before and after the epidemic. This decrease, however, was not as significant as the previous NPO. Total Comments was the only variable whose average increased after the outbreak. This indicates that, despite the lower size of the online community, it was more participatory.

Despite these findings, a T-test comparing the means of likes, shares, and comments before and after the pandemic found no statistically significant change. Rather, the difference might be attributed to a decrease in the number of posts after the incidence. The T-test results are shown in Table 8. 
Fig. 6 Total DART elements (before and after the pandemic), source: SPSS (2021)

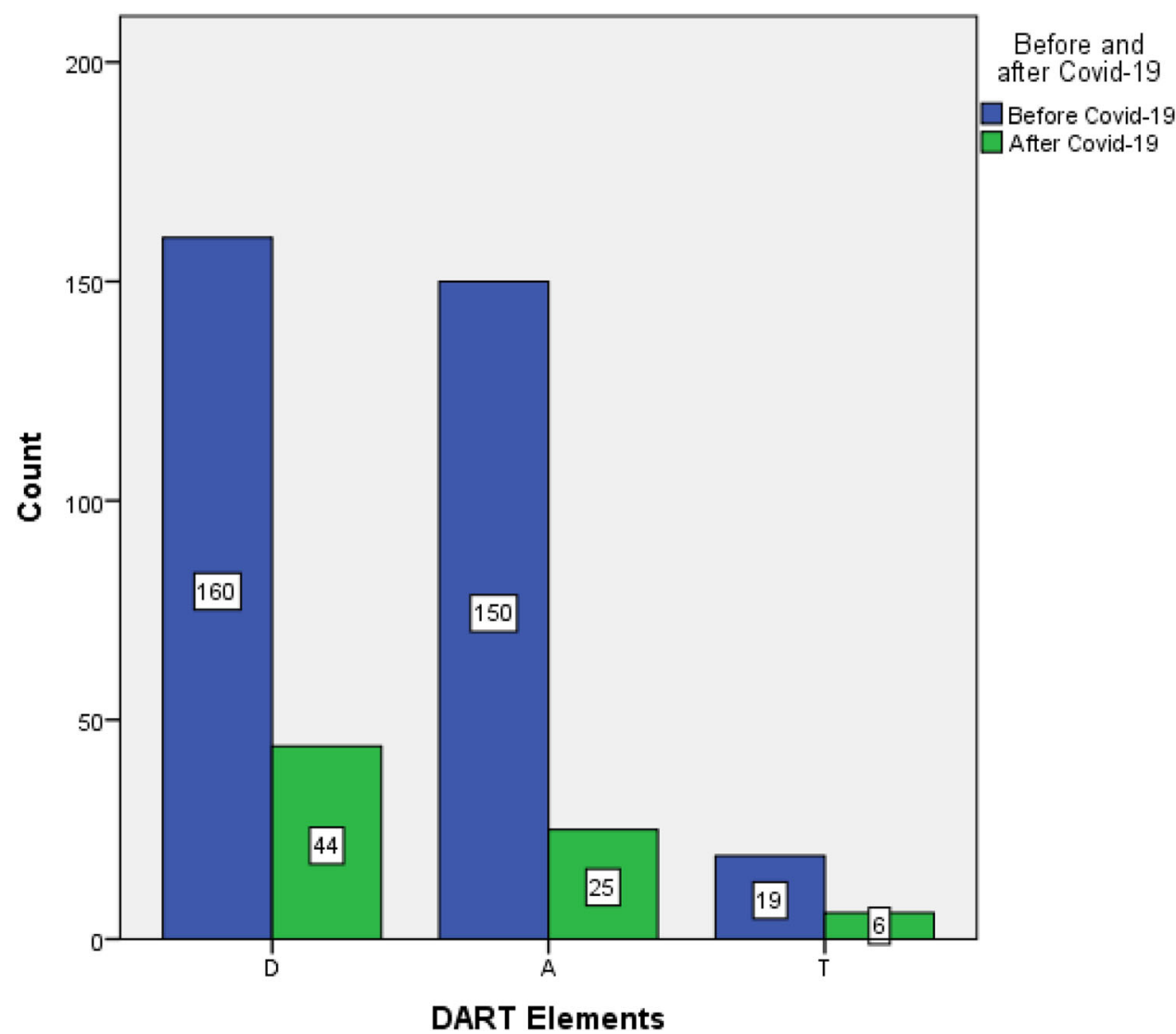

Source: SPSS (2021)
Linear regression before and after COVID-19-NPOCancer

Table 9 shows the summary of the linear regression models before and after the outbreak for the linear regression of models 4, 5 and 6. The models are:

Model 3: Total Shares (Number of Posts) (Dependent Variable) x Total DART (Number of Posts) (Independent Variable).

Model 4: Total Comments (Number of Posts) (Dependent Variable) x Total DART - (Number of Posts) (Independent Variable).

Before the Pandemic-NPO-Cancer Model 3 has a high predictive power (adjusted $\mathrm{R}^{2}=0.731$ ). The DART elements predicted the variable Total Shares with a $\mathrm{p}$-value of 0.001 .

The predictive power of model 4 was fairly low before the pandemic (adjusted $\mathrm{R}^{2}=0.288$ ). The $\mathrm{p}$-value was $<$ 0.001 , indicating that the DART components were unable to predict Total Comments, showing that these variables had no effect on donation intention before to the pandemic.
After the Pandemic Outbreak-NPO-Cancer Model 3 had a high predictive power (adjusted $\mathrm{R}^{2}=0.896$ ). The p-value was $<0.001$, showing that the DART elements were able to significantly predict Total Shares, impacting donor intention to engage after the pandemic outbreak.

Finally, the predictive power of model 4 was likewise very good (adjusted $\mathrm{R}^{2}=0.921$ ). $<0.001$ was the $\mathrm{p}$-value. According to the model, the DART components were able to accurately predict Total Comments after the pandemic outbreak.

Table 10 summarizes and contrasts the variables prior to and after the pandemic outbreak.

The elements of value co-creation affected the amount of shares before and after the pandemic outbreak, as evidenced with this NPO's research. Before the outbreak, the amount of comments, on the other hand, did not stir consumers' interest sufficiently to persuade them to donate. This might be explained by the cognitive work necessary for people to leave a remark on a post and a comment (Saxton, 2008). After the outbreak, as people spent more time online (and at home), value co-creation actions influenced both the number of shares and comments. 
Fig. 7 Total Shares (before and after the pandemic), source: SPSS (2021)

Fig. 8 Total Likes (before and after the outbreak), source: SPSS (2021)

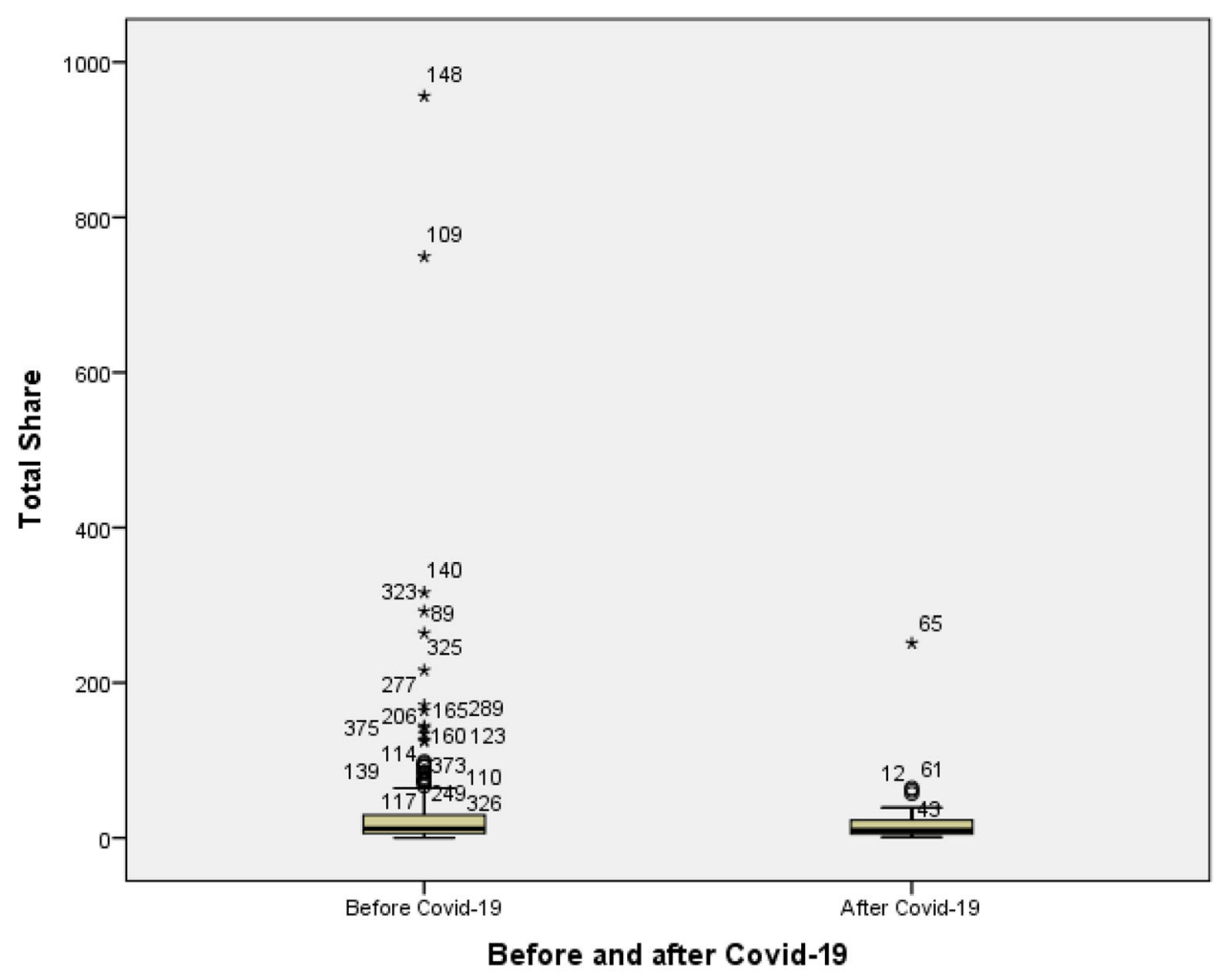

Source: SPSS (2021)

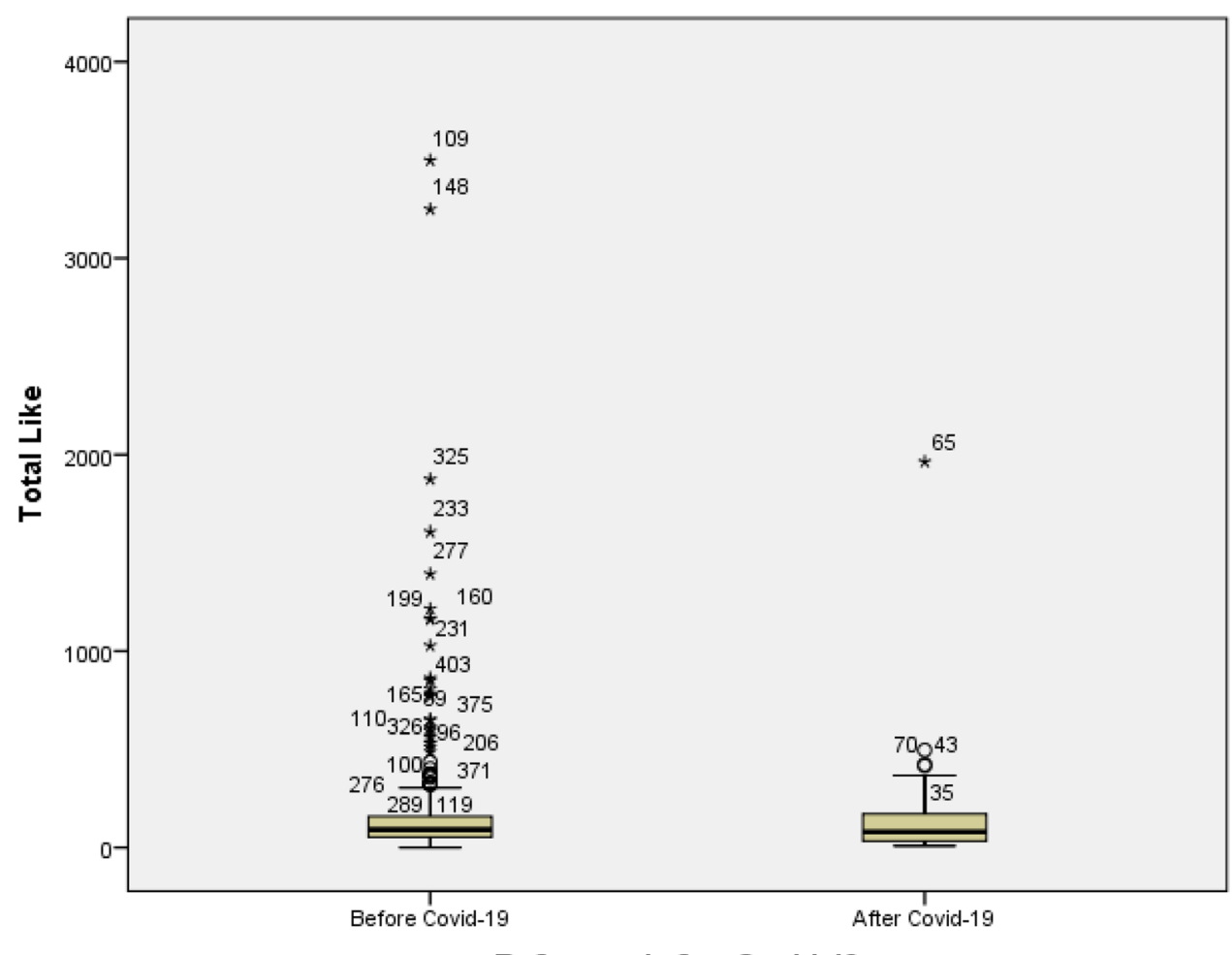

Source: SPSS (2021)

Before and after Covid-19 
Fig. 9 Total Comments (before and after the pandemic), source: SPSS (2021)

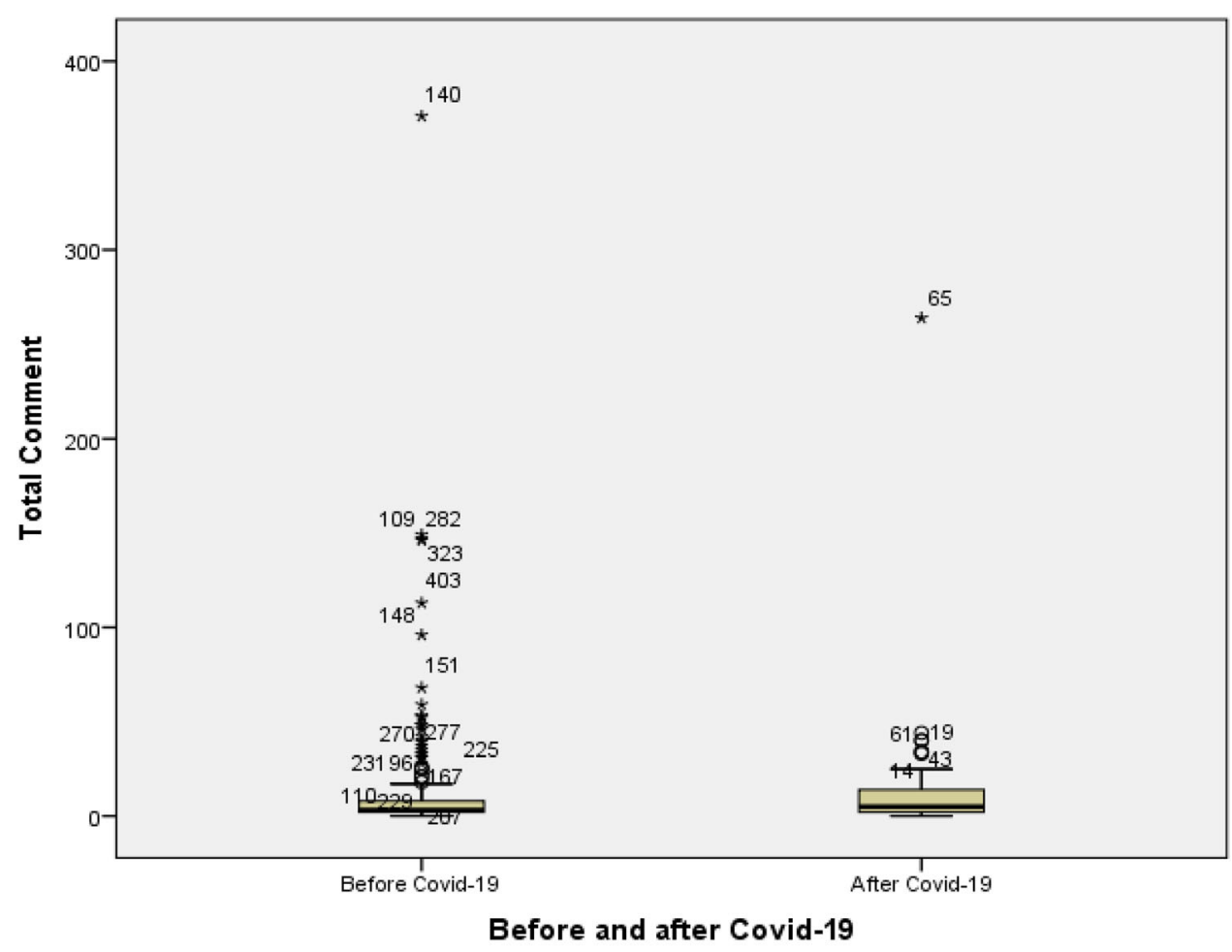

Source: SPSS (2021)

Table 8 T-test of engagement before and after the pandemic outbreak

\begin{tabular}{|c|c|c|c|c|c|c|c|}
\hline & & \multirow[t]{2}{*}{$\mathrm{t}$} & \multirow[t]{2}{*}{ Sig. (2 tailored) } & \multirow[t]{2}{*}{ Mean difference } & \multirow[t]{2}{*}{ Standard error } & \multicolumn{2}{|c|}{ 95\% Standard confidence } \\
\hline & & & & & & Inferior & Superior \\
\hline Like & Equal var. assumed & .794 & .427 & 32.978 & 41.51 & 48.626 & 114.584 \\
\hline Share & Equal var. assumed & 1.298 & .195 & 11.544 & 8.89 & 5.937 & 29.025 \\
\hline Comment & Equal var. assumed & .660 & .510 & 2.368 & 3.59 & 9.426 & 4.689 \\
\hline
\end{tabular}

Source: Authors (2021)

\section{Conclusion}

Managers have recognized the benefits and pitfalls of including donors into their marketing strategy. Marketing in non-profit organizations appears to be led by a consumer-centred mindset of value co-creation. Another aspect is communication between the NPO and society. It is not enough to simply manage the NPO with transparency, social responsibility, and indicators. It is not just the formal organization that matters. The importance also lies in developing the NPO's identity.

The NPO's characteristics and causes might influence the appeal and strategy used to attract donors. It is worth mentioning that the study's results may be expanded beyond the reported findings, emphasizing the importance of emotional appeal in an organization's strategy. When children are involved in this appeal, emotions play a significant role. Thus, managers have realized the advantages and challenges of including donors into the marketing strategy process and also for value co-creation in order to fulfil the NPO's social mission.

Another finding from the qualitative phase concerns donor intent in the context of a NPO. Online users that start following (online) a non-profit organization are generally people who already support charity causes, are engaged in volunteer work, or have an interest in promoting and endorsing the given cause.

Donations made through social media face additional challenges. According to Chen et al. (2019), imitation of social talents fosters empathy, which is the "common ground" that drives traditional offline donations. Hence, it is necessary to develop different and more modern 
Table 9 Intensity of interaction as a response to DART elements

\begin{tabular}{lll}
\hline Before the COVID-19 & Model 4 (DART to Shares) & Model 5 ( DART to Comments) \\
\hline Frequency & $405(100 \%)$ & $405(100 \%)$ \\
$\mathrm{R}$ & 0.885 & 0.690 \\
$\mathrm{R}^{2}$ & 0.732 & 0.290 \\
Adjusted $\mathrm{R}^{2}$ & 0.731 & 0.288 \\
ANOVA (F) & $894,337^{* * *}$ & $133.865^{* * *}$ \\
Constant (B) & $-3,880$ & 2.019 \\
Shares, comments (B) & $.190^{* * *}$ & $.043^{* * * *}$ \\
\hline After the COVID-19 outbreak & Model 4 (DART to Shares) & Model 5 ( DART to comments) \\
\hline Frequency & $405(100 \%)$ & 405 (100\%) \\
R & 0.947 & 0.960 \\
$\mathrm{R}^{2}$ & 0.897 & 0.922 \\
Adjusted R & 0.896 & 0.921 \\
ANOVA (F) & $638.331^{* * *}$ & $863.511^{* * *}$ \\
Constant (B) & 0.499 & $5.636^{* * *}$ \\
Shares, comments (B) & $0.121^{* * *}$ & $0.125^{* * *}$ \\
\hline
\end{tabular}

**** $\rho<0.001$

${ }^{* *} \rho<0.05$

${ }^{*} \rho<0.1$

Source: Authors (2021)

Table 10 NPO-Cancer results

\begin{tabular}{llll}
\hline Period & Model & Variables & Result \\
\hline Before the pandemic & Model 3 & DART vs Total Shares & Total Shares were influenced by DART \\
& Model 4 & DART vs Total Comments & Total Comments were not influenced by DART \\
After the pandemic outbreak & Model 3 & DART vs Total Shares & Total Shares were tightly influenced by DART \\
& Model 4 & DART vs Total Comments & Total Comments were tightly influenced by DART
\end{tabular}

Source: Authors (2021)

strategies to include donors or future donors and keep or increase donations. The attitude influences the intention favourably, which is why attitudes such as "shares" and "comments" were identified as attitudes that represent donation intention.

The quantitative study showed that in general, the DART elements were able to influence Comments and Shares in both NPOs, but only after the outbreakalthough with varying strength. Total Shares and Total Comments could not be predicted in any of the NPOs before the outbreak. This is a relevant change in behaviour that occurs after the outbreak and must be considered by NPOs.

According to Sing et al., (2019), advances in computer technology have changed the world in several ways. For example, communication is done via the internet with just one click. As stated by Alsaleh (2019), two simple ways to send a message is through a click button or a double-click. Further, considering that a holistic perspective of DART was taken on its influence in donation practices, which are here represented by online interactions (Shares and Comments), it is possible to say that value co-creation actions were able to involve online users and possibly influence or keep donations.

This study has added to the literature by focusing on the interaction of actors from the perspective of the organization as a value proposer as well as a recipient of the cocreated value. This study introduces a perspective of discourse transformation by examining the practices of donation, fundraising and value co-creation relationship 
before and after the pandemic outbreak. It also helps to shape the perception of value co-creation as a proper marketing strategy mindset, analogous to an orientation.

However, we acknowledge that the results were drawn broadly. This phenomena should be studied further from many angles. In this regard, there is much of potential for further research on donation and intent to donate before, during, and after the COVID-19 pandemic outbreak. The age of the participants (characterization) was a study limitation, since age might influence the co-creation process. As the participants get older, their prior experiences might give them with a more socially inclined viewpoint, having already gone through events that young people are now going through, such as career stability, higher wages, and constituting a family. All of these factors may influence someone's actions, in this sense, also value co-creation.

It would be advisable to pick NPOs from different areas to investigate the phenomenon of donation (including fundraising and intention to donate) and value co-creation. Furthermore, the study did not include risk sharing as a variable that predicts the intention to donate. This opens the possibility for further research on risk sharing to be pursued, especially in other NPOs contexts.

We conclude this study with the following remaining questions to be considered for reflection or investigation:

1. Given that the pandemic led to the loss of many people's permanent employment what strategies may companies employ to increase donations and co-create value during pandemics?

2. What are the motives for volunteer work during the pandemic, and what are the advantages of this volunteer labour in terms of creating social well-being?

Funding We declare that the authors did not receive support from any organization for the submitted work; no funding was received to assist with the preparation of this manuscript; no funding was received for conducting this study; no grants or other support was received.

\section{Declaration}

Conflict of interest The authors declare that they have no conflict of interest.

Ethical approval Our research follows ethical standards.

\section{References}

Ajzen, I. (1991). The theory of planned behaviour. Organizational Behaviour and Human Decision Processes, 50(2), 179-211.

Alisher, E. (2017). Innovative marketing strategy for tourism development. World Scientific News, 88(2), 58-68.
Alsaleh, N. (2019, October). Extension of assistive technology on mobile platform. In 2019 10th IEEE International Conference on Cognitive Info communications (CogInfoCom) p. 415-416.

Angrist, J. D., \& Pischke, J. S. (2008). Mostly harmless econometrics. Princeton.

Avner, M. A. (2016). Advocacy, lobbying and social change. In D. O. Renz (Ed.), The Jossey-Bass handbook of Nonprofit leadership and management (4th ed., pp. 396-426). John Wiley.

Baker, M. J., \& Saren, M. (Eds.). (2016). Marketing theory: A student text (3rd ed.). Sage.

Blouin, M. C., Lee, R. L., \& Erickson, G. S. (2018). The impact of online financial disclosure and donations in non-profits. Journal of Nonprofit and Public Sector Marketing, 30(3), 251-266.

Bryson, J., Sancino, A., Benington, J., \& Sørensen, E. (2017). Towards a multi-actor theory of public value co-creation. Public Management Review, 19(5), 640-654.

Chad, P. (2013). Implementing market orientation in charities: A necessity for survival. Marketing Theory, 13(3), 303-322.

Chen, X., Wu, S., \& Guo, X. (2019). Analyses of factors influencing Chinese repeated blood donation behaviour: Delivered value theory perspective. Industrial Management \& Data Systems, 120(3), 486-507.

Chiplunkar, S. S., Gowda, D. V., \& Shivakumar, H. G. (2020). Adaptation of pharmaceutical marketing and drug promotion practices in times of pandemic COVID-19. International Journal of Health \& Allied Sciences, 9(5), 11.

da Silva, L. C., Mainardes, E. W., Teixeira, A. M. C., \& Júnior, L. C. (2020). Brand orientation of Nonprofit organizations and its relationship with the attitude toward charity and donation intention. International Review on Public and Nonprofit Marketing, 17(3), 353-373.

Dolnicar, S., \& Lazarevski, K. (2009). Marketing in non-profit organizations: An international perspective. International Marketing Review, 26(3), 275-291.

Eisenhardt, K. M. (1989). Building theories from case study research. Academy of Management Review, 14(4), 532-550.

Epstein, M.J., (2018) "Performance Measurement and Management Control: Challenges for Applications and Research in New Settings", Epstein, M.J., Verbeeten, F.H.M. Widener, S.K. (Ed.) Performance Measurement and Management Control: The Relevance of Performance Measurement and Management Control Research (Studies in Managerial and Financial Accounting, Vol. 33), Bingley: Emerald Publishing Limited, p. $3-12$.

Fyall, R. (2016). The power of non-profits: Mechanisms for Nonprofit policy influence. Public Administration Review, 76(6), 938-948.

Ghosh, M. (2019). Determinants of green procurement implementation and its impact on firm performance. Journal of Manufacturing Technology Management, 30(2), 462-482.

Gibbs, G. R. (2014). In U. Flick (Ed.), Using software in qualitative analysis. The SAGE handbook of qualitative data analysis, p. 277-294. London. Sage.

Gregory, G., Ngo, L., \& Miller, R. (2019). Branding for non-profits: Explaining new donor decision-making in the charity sector. Journal of Product \& Brand Management, 29(5), 583-600.

Grönroos, C., \& Ravald, A. (2011). Service as business logic: Implications for value creation and marketing. Journal of Service Management, 22(1), 5-22.

Gummesson, E. (2017). Case theory in business and management: Reinventing case study research. Sage Publications.

Hunt, S. D. (2018). The prospects for marketing strategy and the marketing discipline in Era V: Is the prognosis promising or problematic? Journal of Marketing Management, 34(1-2), 86-95.

Kara, A., Spillan, J. E., \& DeShields, O. W., Jr. (2004). An empirical investigation of the link between market orientation and business 
performance in non-profit service providers. Journal of Marketing Theory and Practice, 12(2), 59-72.

Kashif, M., \& De Run, E. C. (2015). Money donations intentions among Muslim donors: An extended theory of planned behaviour model. International Journal of Nonprofit and Voluntary Sector Marketing, 20(1), 84-96.

Kaur, R., \& Kumar, B. (2017). Market Orientation in non-profit organisations. NMIMS Management Review, 35(3), 55-71.

Kim, C., \& Yang, S. U. (2017). Like, comment, and share on Facebook: How each behaviour differs from the other. Public Relations Review, 43(2), 441-449.

Kohli, A. K., \& Jaworski, B. J. (1990). Market orientation: The construct, research propositions, and managerial implications. Journal of Marketing, 54(2), 1-18.

Kuckartz, U., \& Rädiker, S. (2019). Analysing qualitative data with $M A X Q D A$. Springer International Publishing.

Levine, H., \& Zahradnik, A. G. (2012). Online media, market orientation, and financial performance in non-profits. Journal of Non-Profit \& Public Sector Marketing, 24(1), 26-42.

Lwin, M., \& Phau, I. (2014). An exploratory study of existential guilt appeals in charitable advertisements. Journal of Marketing Management, 30(13-14), 1467-1485.

Macedo, I. M., \& Pinho, J. C. (2006). The relationship between resource dependence and market orientation: The specific case of non-profit organisations. European Journal of Marketing, 40(5), 533-553.

Mahmoud, M. A., \& Yusif, B. (2012). Market orientation, learning orientation, and the performance of non-profit organisations (NPOs). International Journal of Productivity and Performance Management, 61(6), 624-652.

Maier, F., Meyer, M., \& Steinbereithner, M. (2016). Nonprofit organizations becoming business-like: A systematic review. Nonprofit and Voluntary Sector Quarterly, 45(1), 64-86.

Mainardes, E. W., Laurett, R., Degasperi, N. C. P., Lasso, S. V., (2017) External motivators for donation of money and/or goods. International Journal of Nonprofit and Voluntary Sector Marketing, 22(2), e1568.

McColl-Kennedy, J. R., Gustafsson, A., Jaakkola, E., Klaus, P., Radnor, Z. J., Perks, H., \& Friman, M. (2015). Fresh perspectives on customer experience. Journal of Services Marketing, 29(6-7), 430-435.

Modi, P., \& Mishra, D. (2010). Conceptualising market orientation in non-profit organisations: Definition, performance, and preliminary construction of a scale. Journal of Marketing Management, 26(5-6), 548-569.

Namisango, F., Kang, K. (2018) Social media, organisation-community relationships and co-creation: a case of non-profit organizations. In Americas Conference on Information Systems 2018: Digital Disruption, AMCIS 2018.

Neghina, C., Caniëls, M. C., Bloemer, J. M., \& van Birgelen, M. J. (2015). Value cocreation in service interactions: Dimensions and antecedents. Marketing Theory, 15(2), 221-242.

Oliveira, E., \& Panyik, E. (2015). Content, context and co-creation: Digital challenges in destination branding with references to Portugal as a tourist destination. Journal of Vacation Marketing, 21(1), 53-74.

Paramita, W., Rostiani, R., Winahjoe, S., Wibowo, A., Virgosita, R., \& Audita, H. (2021). Explaining the voluntary compliance to COVID-19 measures: An extrapolation on the gender perspective. Global Journal of Flexible Systems Management, 22(Suppl 1), S1-S18.

Payne, A. F., Storbacka, K., \& Frow, P. (2008). Managing the cocreation of value. Journal of the Academy of Marketing Science, 36(1), 83-96.

Pomirleanu, N., Mariadoss, B. J., \& Chennamaneni, P. R. (2016). Managing service quality in high customer contact B2B services across domestic and international markets. Industrial Marketing Management, 55, 131-143.

Prahalad, C. K., \& Ramaswamy, V. (2004). Co-creation experiences: The next practice in value creation. Journal of Interactive Marketing, 18(3), 5-14.

Riyadi, S., Susilo, D., Sufa, S. A., \& Putranto, T. D. (2019). Digital marketing strategies to boost tourism economy: A case study of Atlantis land Surabaya. Humanities \& Social Sciences Reviews, 7(5), 468-473.

Salkind, Neil J. (2016) Statistics for People Who (Think They) Hate Statistics. The University of Kansas. SAGE Publications. p. 552.

Samiee, S., \& Chirapanda, S. (2019). International marketing strategy in emerging-market exporting firms. Journal of International Marketing, 27(1), 20-37.

Saxton, B. (2008). Information tools: Using blogs, RSS, and wikis as professional resources. Young Adult Library Services, 6(2), $27-29$.

Schumpeter, J. A. (2010) Capitalism, socialism and democracy.1st Edition, London, Routledge Classics. https://doi.org/10.4324/ 9780203857090.

Stock, J. H., \& Watson, M. W. (2015). Introduction to econometrics. $3 r d$ (updated). Longman.

Tam, L. T., Ho, H. X., Nguyen, D. P., Elias, A., \& Le, A. N. H. (2021). Receptivity of governmental communication and its effectiveness during COVID-19 pandemic emergency in vietnam: A qualitative study. Global Journal of Flexible Systems Management, 22(Suppl 1), S45-S64.

Tihanyi, L. (2020). From "that's interesting" to "that's important." Academy of Management Journal, 63(2), 329-331.

Ufua, D. E., Osabuohien, E., Ogbari, M. E., Falola, H. O., Okoh, E. E., \& Lakhani, A. (2021). Re-strategising government palliative support systems in tackling the challenges of COVID-19 lockdown in Lagos State, Nigeria. Global Journal of Flexible Systems Management, 22(Suppl 1), S19-S32.

Valtakoski, A. (2019). The evolution and impact of qualitative research in Journal of Services Marketing. Journal of Services Marketing, 34(1), 8-23.

Van Puyvelde, S., Caers, R., Du Bois, C., \& Jegers, M. (2016). Managerial objectives and the governance of public and nonprofit organizations. Public Management Review, 18(2), 221-237.

Varadarajan, R. (2010). Strategic marketing and marketing strategy: Domain, definition, fundamental issues and foundational premises. Journal of the Academy of Marketing Science, 38(2), 119-140.

Vargo, S. L., \& Lusch, R. F. (2004). Evolving to a new dominant logic for marketing. Journal of Marketing, 68(1), 1-17.

Vargo, S. L., \& Lusch, R. F. (2008). Why "service"? Journal of the Academy of Marketing Science, 36(1), 25-38.

Vargo, S. L., \& Lusch, R. F. (2016). Institutions and axioms: An extension and update of service-dominant logic. Journal of the Academy of Marketing Science, 44(1), 5-23.

Vergara, I. G. P., Gómez, M. C. L., Martínez, I. L., \& Hernández, J. V. (2021). Strategies for the preservation of service levels in the inventory management during COVID-19: A case study in a company of biosafety products. Global Journal of Flexible Systems Management, 22(Suppl 1), S65-S80.

Vieira, V. A., de Almeida, M. I. S., Agnihotri, R., \& Arunachalam, S. (2019). In pursuit of an effective B2B digital marketing strategy in an emerging market. Journal of the Academy of Marketing Science, 47(6), 1085-1108.

Wright, L. T., Robin, R., Stone, M., \& Aravopoulou, D. E. (2019). Adoption of Big Data technology for innovation in B2B marketing. Journal of Business-to-Business Marketing, 26(3-4), 281-293. 
Zhang, X., \& Chen, R. (2008). Examining the mechanism of the value co-creation with customers. International Journal of Production Economics, 116(2), 242-250.

\section{Key Questions}

1. What effect does age have on the intention to donate in the third sector?

2. What is the sample's opinion on the variables that promote value co-destruction throughout the third sector

Publisher's Note Springer Nature remains neutral with regard to jurisdictional claims in published maps and institutional affiliations.

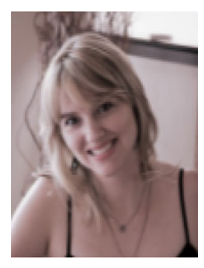

Renata Klafke (UFPR) nena.klafke@gmail.com / Renata.Klafke@farroupilha.ifrs.edu.br.She holds a Bachelor's degree in International Business Administration, a Master of Science in Industrial Engineering, and a $\mathrm{PhD}$ in Business Management (Marketing).Renata has worked in international business management since 2004, dealing with import and export procedures in national and multinational companies. She lectured International Business Management disciplines at the Universidade Estadual de Ponta Grossa (UEPG) in Brazil for 5 years (from 2013-2018). She now lectures at the Instituto Federal do Rio Grande do Sul (IFRS).Research interests refers to: Case Study Methodology, International Marketing, Cultural Intelligence, Education, and Industrialisation.

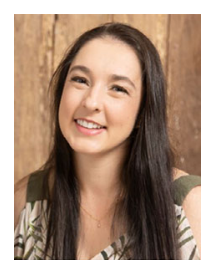

Claudia Tania Picinin (UTFPR)She obtained a bachelor's degree in Business Management. MBA in Business Administration and Logistics. She is an Industrial Management - Knowledge and Innovation expert. $\mathrm{PhD}$ in Business Management (at Positivo University).Claudia Picinin is a Professor at UTFPR University - Campus Ponta Grossa - Brazil - at the Production Engineering Department.Specialties: Workplace Quality Management, Knowledge Management and Business Management.

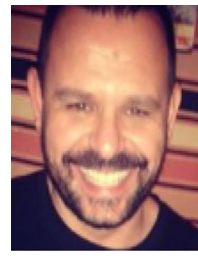

Diego Gonzale Chevarria He holds a bachelor's degree in Business Management. a Master of Science in Business Management, and a PhD in Business Management (Innovation, Technology and Sustainability).He is a Basic, Technical, and Technological Education Professor at the Federal Institute of Rio Grande do Sul (IFRS), Campus Farroupilha.Specialties: Quantitative Research Methods, Innovation and Technological Dissemination. 